\title{
Segmented Power Supply Preset Control Method of High-Speed Rail Contactless Traction Power Supply System considering Regenerative Braking Energy Recovery
}

\author{
Ruoqiong Li $\mathbb{D},{ }^{1}$ Junjie Wang $\mathbb{D},{ }^{1}$ Xuan Zhao ${ }^{D},{ }^{1}$ and Xin $\mathrm{Li} \mathbb{D}^{2}$ \\ ${ }^{1}$ School of Automation \& Electrical Engineering, Lanzhou Jiaotong University, Gansu 730070, China \\ ${ }^{2}$ School of New Energy \& Power Engineering, Lanzhou Jiaotong University, Gansu 730070, China \\ Correspondence should be addressed to Ruoqiong Li; liruoqiong26@163.com and Junjie Wang; 15139152002@163.com
}

Received 16 October 2020; Revised 23 November 2020; Accepted 8 December 2020; Published 21 December 2020

Academic Editor: Licheng Wang

Copyright (c) 2020 Ruoqiong Li et al. This is an open access article distributed under the Creative Commons Attribution License, which permits unrestricted use, distribution, and reproduction in any medium, provided the original work is properly cited.

\begin{abstract}
For high-speed rail with high energy consumption, the recovery and utilization of regenerative braking energy is essential to improve the energy consumption of high-speed rail. As a technical link, the energy bidirectional feed inductively coupled power transfer (ICPT) system can realize the regenerative braking energy recovery of the contactless traction power supply system. Furthermore, considering that the braking energy of the high-speed rail is the largest when entering the station during the whole line operation, the braking section of the station is mainly considered. This paper proposes a preset control method for segmented power supply of the energy bidirectional feed ICPT system considering regenerative braking energy recovery. By establishing the steady-state mathematical model of the bidirectional ICPT system, the influence of the internal phase-shift angles $\varphi_{1}$ and $\varphi_{2}$ and the external phase-shift angle $\gamma$ on the operating state of the system is analyzed. To realize system synchronization under the operation of EMUs, a train braking model is established through force analysis, and a power preset controller is designed to realize the synchronous control of the power flow of the bilateral system. According to the braking process of the train entering the station, the switching control method of the segment coil under the different conditions of the single train entering the station and the multitrain entering the station is proposed to ensure the reliability and flexibility of the train power supply. The simulation results of the $350 \mathrm{~kW}$ ICPT system simulation model show that the system can operate stably when the power transmission simulation is switched, and the transmission efficiency can reach $89 \%$, which proves the feasibility of the control method. Energysaving estimates show that a single train can recover about 200-300 kWh of electric energy during single braking. The comparison with the measured data verifies the accuracy of the modeling in this paper.
\end{abstract}

\section{Introduction}

Electrified rail transit system is an important load of the power system. According to statistics, by the end of 2018, China's high-speed railway operation mileage has reached $29000 \mathrm{~km}$, and the total power consumption of the railway in 2018 is up to 71.1 billion $\mathrm{kWh}$, of which high-speed railway consumes about $40 \%$ [1].

Energy-saving operation is the key and difficult point for the further development of rail transit at present. It is of great significance to research renewable energy storage in the field of high-speed railway, heavy-duty railway, long ramp line, or railway terminal station. As a braking system, regenerative braking is an effective energy-saving operation measure. It can reduce the speed by reversing the operation of the motor. Regenerative braking technology uses the motor of the train as the generator to convert mechanical energy into electrical energy and return it to the power grid. Moreover, according to the analysis of measured data, the proportion of regenerative energy consumption increases with the increase of braking initial speed [1]. For high-speed railway, the recycling of regenerative braking energy is important to improve the energy consumption of highspeed railway [2].

In the aspect of high-speed railway traction power supply, at present, the electric locomotive is mainly driven 
by the catenary, and the excessive meeting of trains will impact the catenary and onboard electric equipment. In addition to the impact of extreme weather, the problems of pantograph wear, spark, and corrosion are also serious. The contactless power supply adopts the medium-voltage DC power supply system, which overcomes the problems of the traditional single-phase AC contact power supply method such as bow-to-network coupling, negative sequence, excessive phase separation, contact line galloping, and complex regenerative braking energy storage and utilization schemes. According to the principle of electromagnetic induction, ICPT technology supplies the electric energy to the locomotive in a contactless way through the inductive coupling between coils. Furthermore, the characteristics of the ICPT system, such as short distance, high power, and high efficiency, determine its good development prospects in the field of rail transit [3]. When the train is at rest, Professor Pugi Luca of Italy proposed the innovative application of radio energy transmission technology in the railway "Parking" function (power collection under static state) [4]. South Korea has designed an MW level train contactless real-time current collection system experimental line, and its system efficiency can reach $82.7 \%$ [5]. Professor Seung Beop Lee's team improved the existing ferrite energy transmission module while meeting the system electromagnetic field strength, magnetic saturation, and induced voltage, optimized the design framework of railway wireless charging system, saved construction cost [6], and further improved the construction feasibility of railway contactless traction power supply system.

For contact traction power supply system regenerative braking energy recovery, there are three common solutions: energy consumption, feedback, and recovery. The energyconsuming structure is simple and easy to realize, but this solution is not energy-saving. The feedback type is mainly divided into direct feedback to the power grid and other trains using the same bridge arm. Although the cost is saved, the impact on the power grid is large, and the harmonic problem is serious. Professor Pugi Luca studied the basis of the existing train model of energy feedback of contact traction system. Aiming at two trains performing their tasks in the opposite direction on the same line, considering feeders and different types of reversible and irreversible substations, a simple and efficient model was obtained [7]. Besides, a control strategy with feedforward control is introduced into the energy storage system to suppress bus voltage fluctuations. By introducing a nonlinear interference observer (NDO), the shortcomings of traditional feedforward control methods that require remote measurement are solved [8]. In the recovery scheme, the energy storage device is used to realize energy storage and dispatching, and peak and valley reduction can be realized, which is a feasible scheme [9-14]. For the recycling scheme, some scholars put forward an energy storage scheme and control strategy of traction power supply system based on railway power regulator, which solves the problem of negative sequence and harmonic current compensation after the energy storage device is connected to the traction power supply system [15]. Also, a coordinated control strategy is proposed by combining the supercapacitor with the railway regulator to solve the problem of runaway discharge of the supercapacitor [16]. In the aspect of the battery management system, some scholars proposed an adaptive square root Unscented Kalman Filter algorithm based on the secondorder Thevenin equivalent circuit model, which improves the accuracy of battery state estimation [17]. The intervention of the energy storage system increases the utilization space of the regenerative braking energy of the train. In the multitrain operation system considering the ground energy storage system, the research on the energy-saving operation of the train has a deeper field and significance. In addition, the hybrid energy storage system has been widely used because of its high efficiency. Professor Wang Kai's team proposed an improved state of charge (SOC) control energy allocation strategy for the hybrid energy storage system of electric vehicles (EV), which improves energy utilization and reduces the battery aging effect [18].

Research on regenerative braking energy recovery of contactless traction power supply system is very rare. Besides, the traditional ICPT system can only achieve a oneway flow of energy and complete one-way traction power supply and cannot provide a feedback channel for regenerative braking energy. Therefore, the ICPT system with energy bidirectional feed is the key to solve the problem of contactless traction power supply regenerative braking energy recovery. Its bidirectional energy feedback characteristic is first proposed to be used in the practical application environment of V2G [19], which can solve the danger brought by plug-in charging and achieve the best energy scheduling. Based on the application background of rail transit, the forward transmission mode of bidirectional ICPT system can realize traction power supply, and the reverse transmission mode provides a recovery channel for regenerative braking energy. While the traditional disadvantages of contact traction power supply system are solved, it is convenient to realize the feedback, recovery, and utilization of regenerative braking energy, which provides strong technical support for the early realization of transportation energy Internet.

At present, the common bidirectional ICPT system control methods need real-time communication to ensure the synchronization of the bidirectional system, which brings great economic and technical problems. In this regard, Professor Udaya K. Madawala proposed a method to adjust the power flow direction by detecting the active and reactive power in the resonance network without real-time communication and only using a controller at the secondary side, but the current distortion rate is very high [20]. Chen Kainan's team at Tsinghua University has made a comprehensive study on the bidirectional ICPT system. In [21], the efficiency optimization control strategy of the bidirectional ICPT system with multiple degrees of freedom is first proposed. However, it still needs real-time communication to achieve synchronization. In [22], a method based on disturbance and observation is proposed to realize the synchronization of bilateral control signals. Reference [23] can realize phase synchronization and maximum efficiency point tracking independent of real-time wireless 
communication. However, the above control strategies still need weak wireless communication to identify the mutual inductance value. Combined with the actual situation of high-speed rail operation, the communication cost is very high, which is not suitable for the field of rail transit. In terms of modeling of induction power transmission system, Professor Pugi Luca's team innovatively proposed that the system model should be equivalent to the lumped mechanical model, and then the conventional modal analysis method used to study the mechanical vibration system was used to optimize it [24], which provided a new idea for the modeling of bidirectional ICPT system.

In addition, the high-speed rail runs fast, the traction power is high, and the power supply process is dynamic, so the design of the power supply coil should ensure the stability and efficiency of the system. There are two types of power supply coil structure in the ICPT system: long rail type and segmented type. The structure of the long rail coil is simple, but there are some problems, such as low utilization rate, large coil impedance, and electromagnetic compatibility. The single unit capacity of the segmented coil is small, which can realize time-sharing segmented power supply and has higher reliability. Therefore, in practical application, the segmented coil is more ideal [25-27]. At present, the ICPT system subsection power supply is mainly based on one-way power flow to load position detection and coil subsection control research. For the sake of my knowledge, the energy bidirectional feed ICPT system has not yet shown a typical subsection power supply scheme.

Given the above problems, this paper divides the regenerative braking process of the train according to the characteristic curve, according to the energy flow relationship of the braking process, through the onboard controller responsible for the adjustment of the power flow size and direction of the converter on the side of the train and the ground controller responsible for the power control, provides the switching logic to the ground coil switching, and obtains a sectionalized power supply line suitable for the regenerative braking energy recovery of the high-speed railway cycle power preset switching control method. Firstly, the energy bidirectional feed ICPT system with a segmented power supply is introduced, and its steady-state mathematical model is established. The relationship between the transmission power and the phase-shift angle of the converter is analyzed. Secondly, the three-stage braking model of the train is established by force analysis. According to the braking model, the power flow control method is introduced, and the sectional coil control method for a single train and multitrain operation is proposed, respectively. Finally, through the establishment of a simulation model in MATLAB/Simulink, the feasibility of the control method is verified, and the energysaving is estimated.

\section{Notation}

The notation system is composed of three parts: symbols, parameters, and decision variables. The main purpose of the system is to help query symbols in equations. The interpretation of symbols may be repeated in some places in this paper to achieve better understanding.

Symbols

ICPT: Inductively coupled power transfer

EMU: Electric multiple units.

\section{Parameters}

$\omega$ : The angular frequency of converter

$M$ : The coil mutual inductance

$\dot{u}_{1}$ : Fourier expansion of primary converter output voltage

$\dot{u}_{2}$ : Fourier expansion of secondary converter output voltage

$U_{1}$ : The fundamental component in the output voltage of the primary converter

$U_{2}$ : The fundamental component in the output voltage of the secondary converter

$I_{2}$ : The phasor of current in secondary resonance coil $I_{2}$ : The output current

$\gamma$ : The phase-shifted phase angle between two-side converter drive signals

$\varphi_{1}$ : The internal shifted phase angle between primary converter drive signals

$\varphi_{2}$ : The internal shifted phase angle between secondary converter drive signals

$P_{1}$ : The input active power

$Q_{1}$ : The input reactive power

$P_{2}$ : The output active power

$Q_{2}$ : The output reactive power

$\theta_{P}$ : The power phase angle

$P_{\text {in: }}$ : The input power considering loss

$P_{\text {out }}$ : The output power considering loss

$\eta_{\text {all }}:$ The overall efficiency of bidirectional ICPT system

$G$ : The train gravity

$N$ : The rail supporting force

$F_{q}$ : The train traction

$W_{0}$ : The basic resistance

$W_{f}$ : The additional resistance

$W_{s}$ : The additional tunnel resistance

$W_{r}:$ The additional curve resistance

$W_{i}$ : The additional ramp resistance

$W_{z}$ : The regenerative braking force

$v_{1}$ : The speed at point 1 by linear interpolation

$v_{2}$ : The speed at point 2 by linear interpolation

$F_{1}$ : The traction at point 1 by linear interpolation

$F_{2}$ : The traction at point 2 by linear interpolation

$f_{q}$ : The traction per unit weight

$m$ : The total train mass

$g$ : The gravitational acceleration

$W_{1}$ : The regenerative braking force at point 1 by linear interpolation

$W_{2}$ : The regenerative braking force at point 2 by linear interpolation

$w_{z}$ : The regenerative braking force per unit weight

$w_{0}$ : The unit basic resistance

$v$ : The real-time train speed

$i$ : The slope of the ramp

$w_{i}$ : The unit ramp additional resistance 
$R:$ The curve radius

$w_{r}$ : The unit curve additional resistance

$L_{s}$ : The length of the train inside the tunnel

$w_{s}$ : The additional resistance per unit tunnel

$c$ : The unit resultant force

$a$ : The train acceleration

$\mu$ : The high-speed rail slewing weight factor

$v_{0}$ : The initial speed of regenerative braking

$v_{s}$ : The speed in each stage of regenerative braking

$s_{n}$ : The distance of each stage of regenerative braking

$t_{0}$ : The initial time of regenerative braking

$t_{n}$ : The time of each stage of regenerative braking

$\eta$ : The comprehensive transmission efficiency of contact traction system

$P_{z}$ : The regenerative braking power

$C_{s}$ : The train resultant force

$P_{s}$ : The traction power

$P_{\text {ref: }}$ The reference power calculated by power model

$P_{0}$ : The measured power

$\left|P_{\text {out }}:\right|$ The absolute value of the output power

$Q$ : The total energy can be recovered during regenerative braking

$P_{n}$ : The power of each stage of regenerative braking.

Decision variables

\section{$A$ : The empirical constant}

$\eta_{G}$ : The transmission efficiency of gearbox

$\eta_{M}$ : The transmission efficiency of traction motor

$\eta_{I}$ : The transmission efficiency of inverter

$\eta_{C}$ : The transmission efficiency of rectifier

$\eta_{T}$ : The transmission efficiency of automotive transformer.

\section{Energy Bidirectional Feed ICPT System}

3.1. System Structure. The segmented power supply structure of the bidirectional ICPT system is shown in Figure 1. The system is composed of onboard part and ground part. When the system is in traction mode, the ground part first obtains $35 \mathrm{kV}$ direct current from the $110 \mathrm{kV}$ AC network side through the AC/DC link, then obtains the standard $2800 \mathrm{~V}$ direct current for the bidirectional ICPT system through the PET link, and finally passes through the magnetic coupling coil transmits energy to the vehicle-mounted part. The vehicle-mounted part obtains $2800 \mathrm{~V}$ direct current and then supplies energy to the electric motor through the DC/AC link to realize train traction. When the system is in the regenerative braking mode, the onboard part of the motor reverses to become a generator, through the $\mathrm{AC} / \mathrm{DC}$ link to obtain the standard $2800 \mathrm{~V}$ direct current for the bidirectional ICPT system, and then the regenerative braking energy is fed back to the ground part through the magnetic coupling coil. The ground part selectively feeds back the regenerative braking energy to the DC bus through the PET link or recovers the regenerative braking energy through energy storage devices such as supercapacitors and batteries. The segmented coil structure is adopted to meet the demand for long-distance power supply of high-speed railway and improve the transmission efficiency.

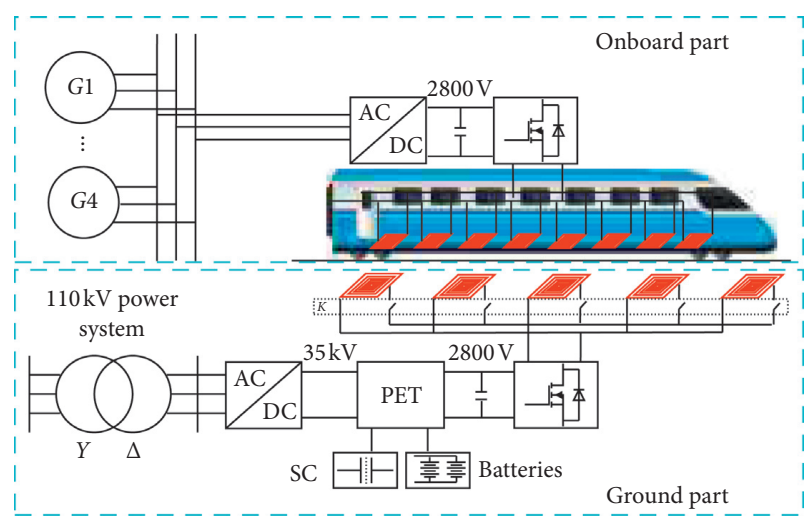

FIGURE 1: Schematic diagram of the bidirectional ICPT system segmented power supply structure.

3.2. Mathematical Model of Bidirectional ICPT System. As shown in Figure 2, compared to a unidirectional ICPT system, there are H-bridge converters composed of MOSFETs (or IGBTs) and diodes in antiparallel on both sides of the bidirectional ICPT system to implement the on-demand conversion process of electrical energy. In the compensation network part, this paper adopts a dual LCC type composite resonance compensation structure, which is more robust than the typical LC series compensation structure. Compared with the LCL compensation structure, the system power of the LCC structure is higher under the same parameters. Therefore, the LCC structure is more suitable for dynamic bidirectional wireless power supply [28]. In Figure 2, $L p 1$ and $L s 1$ are the coil self-inductance, $C_{p 1}, C_{p 2}$, and $L_{p 2}$ are the primary side resonance compensation capacitors and inductances, respectively, $C_{s 1}, C_{s 2}$, and $L_{s 2}$ are the secondary side resonance compensation capacitors and inductances, and $R_{p}$ and $R_{s}$ the equivalent resistances of primary and secondary resonant circuits, respectively. $u_{1}$ and $u_{2}$ are the output voltages of the original secondary converter, $i_{1}$ and $i_{2}$ are the currents in the primary and secondary resonance network, and $U_{1}$ and $U_{2}$ are the DC grid voltage and the train's equivalent DC power supply voltage, respectively.

Control methods for power flow can be divided into two categories. In the first type, the $H$-bridge converter on one side works in the inverting state and the controllable switching devices in the $H$-bridge converter on the other side are all turned off, and the diode is used to work in the rectified state [29], but the work efficiency of this control strategy is greatly affected by load changes.

Phase-shift control is currently a relatively mature control method that can be used in dynamic bidirectional wireless energy transmission systems. When phase-shift control is used, Figure 3 shows the relationship between the control signals $\left(S_{11}, S_{12}, S_{21}\right.$, and $\left.S_{23}\right)$ and system variables when the system is operating in resonance. It can be seen from Figure 3 that $\varphi_{1}$ and $\varphi_{2}$ are the internal phase-shift angles of the control signals of the primary and secondary converters and $\gamma$ is the external shift phase angles between the control signals of the primary and secondary converters, and the upper and lower bridge leg switches on and off complementarily with a duty 


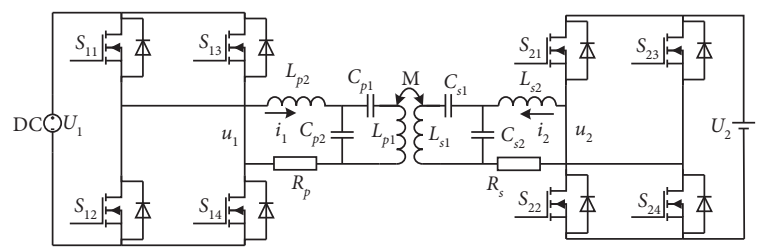

Figure 2: Topology structure of bidirectional ICPT system.

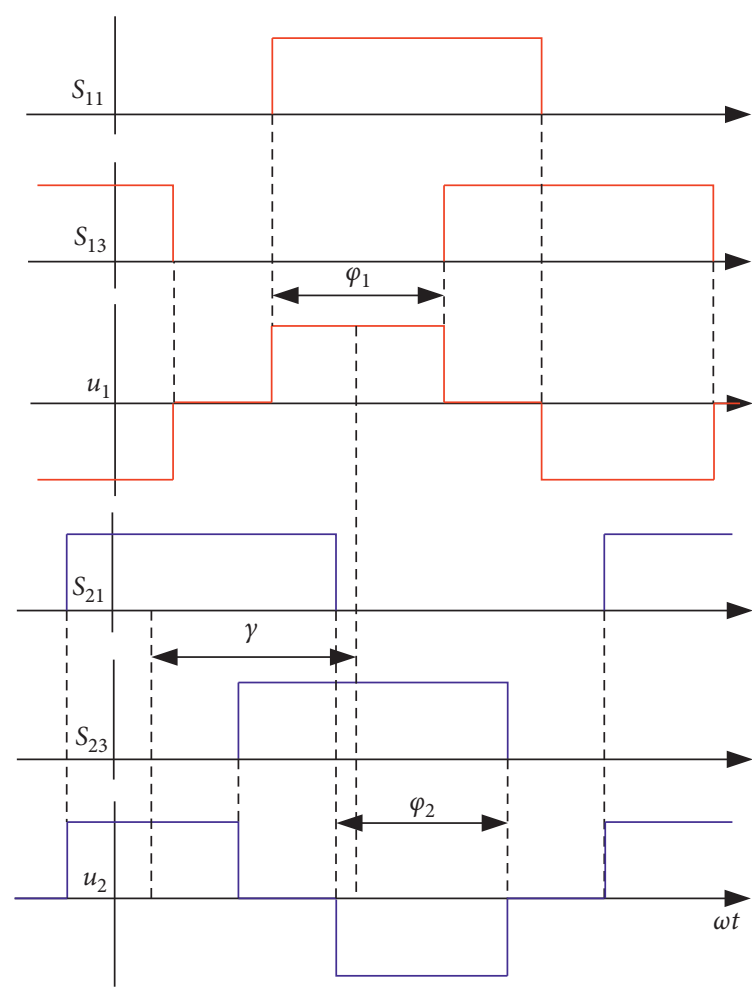

FIGURE 3: Drive signal and output voltage of the converter.

cycle of 0.5 in constant frequency. Besides, in the bidirectional ICPT system, the dead time between drive signals is small and has a little effect on the power transmission characteristics, so it is ignored in the following analysis.

The transmission power of the bidirectional ICPT system is mainly related to the primary and secondary voltages and the fundamental component of the current. Due to the resonant operating characteristics, the higher harmonics contribute little to power transmission. To simplify the analysis, the fundamental harmonic approximation method can be used [30]. The simplified model of the fundamental wave of the bidirectional ICPT system is shown in Figure 4 [28].

It can be seen from the above figure that the output voltages $u_{1}$ and $u_{2}$ of the primary and secondary full bridges are replaced by their fundamental components $\dot{u}_{1}$ and $\dot{u}_{2}$, which can be obtained by Fourier series expansion:

$$
\left\{\begin{array}{l}
\dot{u}_{1}=\frac{2 \sqrt{2}}{\pi} U_{1} \sin \frac{\varphi_{1}}{2} \angle 0, \\
\dot{u}_{2}=\frac{2 \sqrt{2}}{\pi} U_{2} \sin \frac{\varphi_{2}}{2} \angle-\gamma .
\end{array}\right.
$$

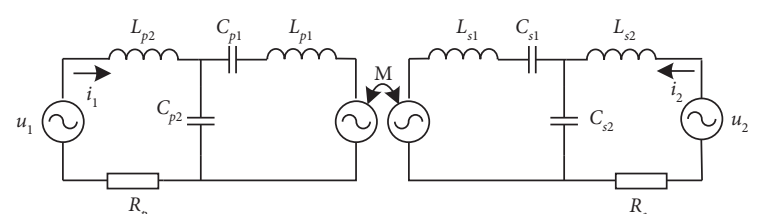

FIGURE 4: Fundamental simplified model of the bidirectional ICPT systems.

Since the bidirectional ICPT system can be used as a good filter for the first harmonic at the resonance frequency, based on the basic harmonic analysis method, when the bidirectional ICPT system is in resonance, $u_{1}$ and $u_{2}$ can be expressed as

$$
\left\{\begin{array}{l}
\dot{U}_{1}=R_{p} \dot{I}_{1}+j \omega M \dot{I}_{2} \\
\dot{U}_{1}=R_{s} \dot{I}_{2}+j \omega M \dot{I}_{1} .
\end{array}\right.
$$

By substituting (2) into (1), the fundamental component of $i_{2}$ can be derived as

$$
\begin{aligned}
\dot{I}_{2}= & \frac{2 \sqrt{2} R_{p} U_{2} \sin \left(\varphi_{2} / 2\right) \cos \gamma}{\pi\left[R_{p} R_{s}+(\omega M)^{2}\right]} \\
& +\frac{2 \sqrt{2} j\left(R_{p} U_{2} \sin \left(\varphi_{2} / 2\right) \sin \gamma-\omega M U_{1} \sin \left(\varphi_{1} / 2\right)\right)}{\pi\left[R_{p} R_{s}+(\omega M)^{2}\right]} .
\end{aligned}
$$

To achieve high-efficiency operation of the bidirectional ICPT system, the value of the out-shifted phase angle $\gamma$ is set to $\pi / 2$ when the power is transferred in the forward direction, and the value of the out-shifted phase angle $\gamma$ is set to when the power is transferred in the reverse direction $3 \pi /$ 2 [28]. Therefore, in order to achieve the synchronous control of the bilateral preset controller and achieve the expected phase synchronization state, the working state with $\gamma$ equal to $\pi / 2$ or $3 \pi / 2$ is set as the control index of the preset controller.

By analyzing the output current $I_{2}$, it can be obtained that the power is affected by the phase-shift angle. From (3), the relationship between the output current $I_{2}$ and the internally shifted phase angles $\varphi_{1}$ and $\varphi_{2}$ and the externally shifted phase angle $\gamma$ is

$$
\begin{aligned}
I_{2}= & \frac{4 \sqrt{2} \omega M U_{1} \sin \left(\varphi_{1} / 2\right) \sin \left(\varphi_{2} / 2\right) \sin \gamma}{\pi^{2}\left[R_{s} R_{p}+(\omega M)^{2}\right]} \\
& -\frac{4 \sqrt{2} R_{p} U_{2} \sin ^{2}\left(\varphi_{2} / 2\right)}{\pi^{2}\left[R_{s} R_{p}+(\omega M)^{2}\right]} .
\end{aligned}
$$

As shown in Figure 5, the maximum value of $I_{2}$ is obtained when $\gamma$ is equal to $\pi / 2$ (the minimum value is obtained when $\gamma$ is equal to $3 \pi / 2$ ); that is, when the phase-shift angle is $\pi / 2$ or $3 \pi / 2$, the forward or reverse transmission power is maximum and the transmission efficiency is optimal, which verifies the accuracy of the modeling in this paper. 


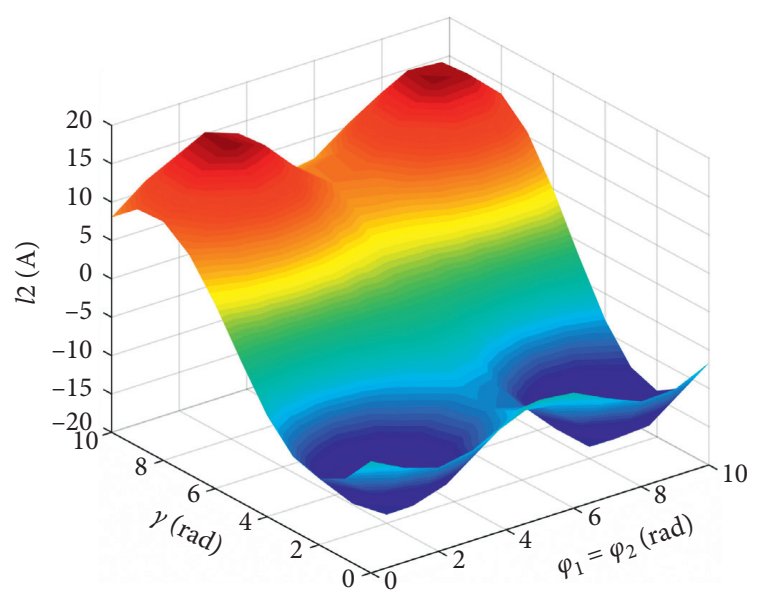

Figure 5: Relationship between $I_{2}$ and $\gamma$.

Because the braking model proposed in this paper corresponds to the real-time power model of the train, the actual control object is the flow and flow direction of active power and reactive power. Therefore, according to equations (2) and (3), the active power and reactive power output by the system can be expressed as

$$
\begin{aligned}
& \left\{\begin{array}{l}
P_{1}=\frac{4 \sqrt{2} R_{s} U_{1}^{2} \sin ^{2}\left(\varphi_{2} / 2\right)}{\pi^{2}\left[R_{s} R_{p}+(\omega M)^{2}\right]} \\
+\frac{4 \sqrt{2} \omega M U_{1} U_{2} \sin \left(\varphi_{1} / 2\right) \sin \left(\varphi_{2} / 2\right) \sin \gamma}{\pi^{2}\left[R_{s} R_{p}+(\omega M)^{2}\right]}, \\
Q_{1}=\frac{4 \sqrt{2} j \omega M U_{1} U_{2} \sin \left(\varphi_{1} / 2\right) \sin \left(\varphi_{2} / 2\right) \cos \gamma}{\pi^{2}\left[R_{s} R_{p}+(\omega M)^{2}\right]} \\
+\frac{4 \sqrt{2} j R_{s} U_{1}^{2} \sin ^{2}\left(\varphi_{2} / 2\right)}{\pi^{2}\left[R_{s} R_{p}+(\omega M)^{2}\right]},
\end{array}\right. \\
& \left\{\begin{array}{l}
P_{2}=\frac{4 \sqrt{2} R_{p} U_{2}^{2} \sin ^{2}\left(\varphi_{2} / 2\right)}{\pi^{2}\left[R_{s} R_{p}+(\omega M)^{2}\right]} \\
-\frac{4 \sqrt{2} \omega M U_{1} U_{2} \sin \left(\varphi_{1} / 2\right) \sin \left(\varphi_{2} / 2\right) \sin \gamma}{\pi^{2}\left[R_{s} R_{p}+(\omega M)^{2}\right]}, \\
Q_{2}=\frac{4 \sqrt{2} j R_{s} U_{1}^{2} \sin ^{2}\left(\varphi_{2} / 2\right)}{\pi^{2}\left[R_{s} R_{p}+(\omega M)^{2}\right]} \\
-\frac{4 \sqrt{2} j \omega M U_{1} U_{2} \sin \left(\varphi_{1} / 2\right) \sin \left(\varphi_{2} / 2\right) \cos \gamma}{\pi^{2}\left[R_{s} R_{p}+(\omega M)^{2}\right]} .
\end{array}\right.
\end{aligned}
$$

The power phase angle is defined here to make the external phase-shift angle $\gamma$ between converters consistent with the flow direction of output power [20].

$$
\theta_{P}=\arccos \left(\frac{P_{2}}{\sqrt{P_{2}^{2}+Q_{2}^{2}}}\right) \text {. }
$$

When the system is fully tuned, the reactive power can be ensured to be zero by adjusting the power phase angle $\theta_{P}$ to 0 or $\pi$. Therefore, when $\theta_{P}$ is 0 or $\pi$, it corresponds to the maximum value of the forward and reverse transmissions of the system. Combining the above analysis, it can be concluded that $\theta_{P}$ of 0 or $\pi$ corresponds to $\gamma$ of $\pi / 2$ or $3 \pi / 2$.

According to [29], the input and output power of the primary and secondary sides of the bidirectional ICPT system should be expressed as (if the switching loss is considered)

$$
\left\{\begin{array}{l}
P_{\text {in }}=P_{1}+P_{\text {loss }-p}, \\
P_{\text {out }}=\left|P_{2}\right|-P_{\text {loss_s }} .
\end{array}\right.
$$

To simplify the analysis, the switching loss is ignored. Thus, the overall work efficiency of the system can be expressed as follows:

$$
\eta_{\text {all }}=\frac{P_{\text {out }}}{P_{\text {in }}}=\frac{\left|P_{2}\right|}{P_{1}} .
$$

Based on the above mathematical analysis of the bidirectional ICPT system, the control method more suitable for the application background of this paper is to control the output side (i.e., train side) to work at 0 or $\pi$ power angle $\theta_{P}$, so as to ensure the high efficiency of the system while eliminating the communication channel to achieve bilateral phase synchronization.

\section{EMU Brake Model}

4.1. EMU Parameters. This article uses CR400BF EMU as an example for calculation. The specific parameters are shown in Table 1 [31]. It has the advantages of the good overall performance of the car body, high safety, and reliability and is currently the world's highest speed EMU operating.

Under normal circumstances, EMUs use a combination of regenerative braking and electropneumatic braking. To verify the proposed control strategy, this paper assumes a pure regenerative braking method to analyze the braking process of the train at the station.

4.2. Force Analysis of EMU. This paper uses a single-particle train model for analysis, as shown in Figure 6.

Except for gravity $G$ and rail support force $N$, there are mainly traction force $F_{q}$, basic resistance $W_{0}$, additional resistance $W_{f}$ (including additional tunnel resistance $W_{s}$, curve additional resistance $W_{r}$, and ramp additional resistance $W_{i}$ ), and braking force $W_{z}$ in the direction of train movement. 
TABLE 1: CR400BF EMU parameters.

\begin{tabular}{lc}
\hline EMU parameters & Parameter value \\
\hline Train mass & $501 \mathrm{t}$ \\
Train formation & $4 \mathrm{M} 4 \mathrm{~T}$ \\
Train length & $200 \mathrm{~m}$ \\
Top speed & $400 \mathrm{~km} / \mathrm{h}$ \\
Maximum braking distance & $6500 \mathrm{~m}$ \\
Motor power & $650 \mathrm{~kW}$ \\
Installed power & $10400 \mathrm{~kW}$ \\
Capacity & 576 \\
\hline
\end{tabular}

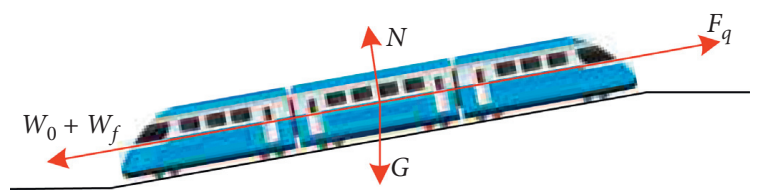

Figure 6: Single-particle train model.

The traction force $F_{q}$ of the train is determined by the traction characteristic curve of the train, which is generally obtained by the manufacturer or the traction experiment. The traction force-speed characteristic curve of CR400BF is shown in Figure 7 [31].

This paper uses linear interpolation to calculate the value. Assuming that two points $\left(v_{1}, F_{1}\right)$ and $\left(v_{2}, F_{2}\right)$ on the traction characteristic curve are known and the point $\left(v_{q}, F_{q}\right)$ is a point between $v_{1}$ and $v_{2}$, then the calculation equation of point traction is as follows:

$$
F_{q}=F_{1}+\frac{\left(F_{2}-F_{1}\right) \times\left(v_{q}-v_{1}\right)}{v_{2}-v_{1}} .
$$

Thus, the traction unit weight is as follows:

$$
f_{q}=\frac{F_{q}}{M g} \text {. }
$$

The calculation method of the train braking force $W_{z}$ differs depending on the braking method. When regenerative braking is used, the value can be calculated by linear interpolation based on the regenerative braking characteristic curve. The regenerative braking characteristic curve of CR400BF is shown in Figure 8 [31].

As above, assuming that two points $\left(v_{1}, W_{1}\right)$ and $\left(v_{2}, W_{2}\right)$ on the traction characteristic curve are known and the point $\left(v_{z}, W_{\mathrm{z}}\right)$ is a point between $v_{1}$ and $v_{2}$, the equation for calculating this point is as follows:

$$
W_{z}=W_{1}+\frac{\left(W_{2}-W_{1}\right) \times\left(v_{z}-v_{1}\right)}{v_{2}-v_{1}} .
$$
is

Therefore, the regenerative braking force per unit weight

$$
w_{z}=\frac{W_{Z}}{m g} .
$$

In addition, the resistance when the train is running needs to be considered. The resistance can be divided into two types: basic resistance $W_{0}$ and additional resistance $W_{f}$.

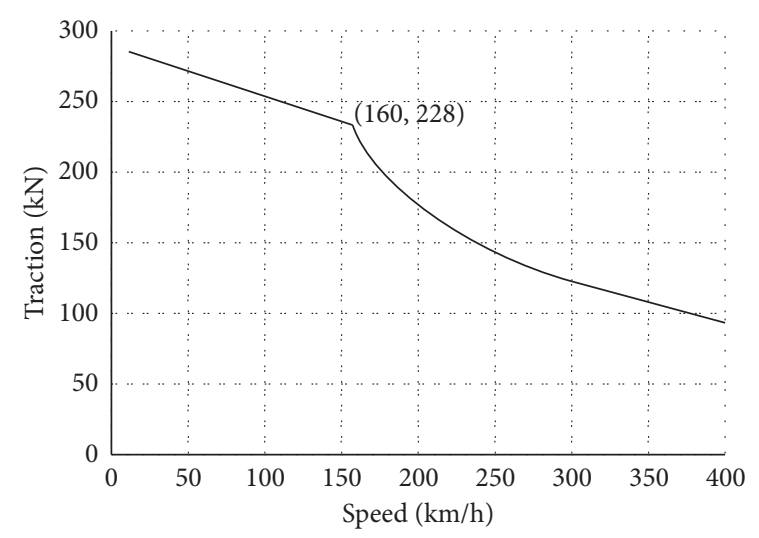

FIgURE 7: CR400BF traction characteristic curve.

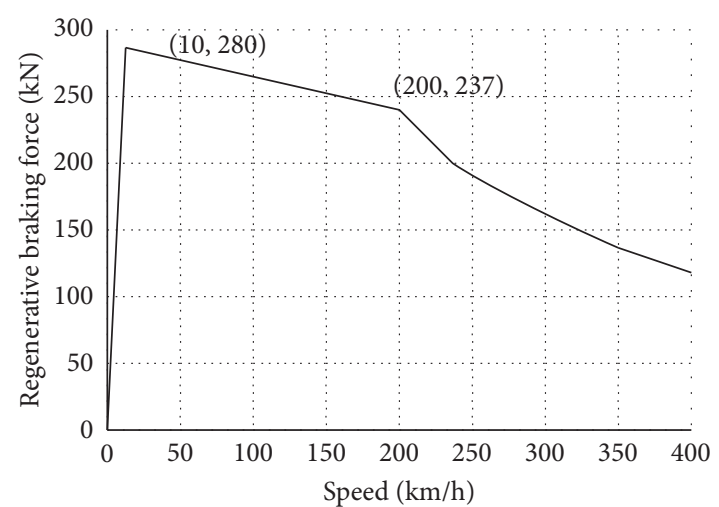

Figure 8: CR400BF regenerative braking characteristic curve.

The basic resistance mainly comes from the frictional resistance of the axle bearing, the rolling friction between the wheelset and the rail, the sliding friction between the wheelset and the rail, the resistance caused by the wheel-rail impact vibration, and the air resistance. The above reference factors are too complicated for analysis, so the basic resistance equation is generally derived from experience. The basic resistance equation of $\mathrm{CR} 400 \mathrm{BF}$ is

$$
w_{0}=3.99+0.0127 v+0.001092 v^{2} .
$$

The additional resistance is mainly affected by the slope of the line, the radius of the curve, and the tunnel. It is based on experience, and the calculation equations of each model are not much different. The equations are as follows:

$$
\begin{aligned}
& w_{i}=\frac{1000 W_{i}}{m g} \approx i, \\
& w_{r}=\frac{A}{R}, \\
& w_{s}=0.00013 L_{s} .
\end{aligned}
$$

Therefore, the resulting unit force $c$ of the train is

$$
c=f_{q}-w_{i}-w_{r}-w_{s}-w_{0}-w_{z} .
$$


4.3. Segment Analysis of Braking Process. Referring to the method of establishing ATP safety braking curve in IEEE1474.1 [32], this paper combines the onboard ATP reaction stage and traction cancellation reaction stage in the traditional five-stage braking process, retains the train inertia stage, combines the braking establishment stage and braking stage, and finally simplifies it into three-stage braking process, that is, equipment response and traction removal stage, train coasting stage, and braking establishment to parking stage.

Stage 1. Equipment response delay and traction removal stage: the ICPT system keeps the energy flow forward, and the bilateral preparations suspend the system and remove power.

Stage 2. During the train idle stage, the ICPT system is suspended.

Stage 3. From the brake establishment to the stop stage, the ICPT system starts to transmit energy in the reverse direction, and the two sides start to control the system with reference to the preset brake model.

According to the typical parameter [32] in IEEE1474.1, the reference time of each stage can be obtained. The resultant force and the working condition of the ICPT system are shown in Table 2.

For the purpose of better analyzing the specific establishment process of the three-stage brake model, the following flowchart analysis is made, as shown in Figure 9. As shown in the figure, firstly, before the braking model starts to work, the initial parameters of the train are sampled and the motion characteristic parameters are extracted, such as initial speed $v_{0}$, ramp $i$, curve radius $R$, and tunnel length $L_{s}$, and then enter into the calculation of the resultant force and real-time speed of the braking model in the first stage. When the time is greater than the set value of the first stage time, the process is judged to enter the second stage of calculation. Similar to the first stage, the resultant force and real-time speed of the second stage are calculated according to the final calculation results of the first stage. When the time is greater than the set value of the second stage time, the process is judged to enter the third stage of operation. In the final braking stage, the judgment process is finished and the three-stage braking model is output when the real-time speed is less than or equal to 0 .

Based on the above analysis, a three-stage braking model is established. Its main purposes are to provide a reliable reference speed and resultant force for the power model, to provide a PWM generator with an out-of-phase angle $\gamma$ that controls the direction of power flow, and to provide switching logic for coil switching control.

First of all, to obtain the $v$-s braking curve at each stage, the relationship between the unit resultant force and the acceleration needs to be found first. When considering the EMU rotation weight coefficient (experience value 0.08 ), the relationship is

$$
a=\frac{g c}{1000(1+\mu)}=\frac{0.00981}{(1+\mu)} c
$$

Therefore, the speed of each stage can be expressed as

$$
v_{s}=\frac{v_{0}}{3.6}-a t=\frac{v_{0}}{3.6}-\frac{0.00981}{(1+\mu)} c t .
$$

The distance of each stage can be expressed as

$$
s_{n}=\int_{t_{0}}^{t_{n}} v \mathrm{~d} t
$$

It can be known from the above analysis that the brake model can obtain the real-time speed $v_{s}$ of the train only by specifying the initial braking speed $v_{0}$ of the train and the braking distance $s_{n}$ at each stage.

\section{Control Strategy}

Preset control mainly includes an onboard controller and ground controller, as shown in Figure 10. Among them, the onboard controller is mainly responsible for adjusting the power flow size and direction of the onboard side ICPT system, and the braking model provides the core reference for the control strategy. Besides power control, the ground controller also needs to provide the switching logic of the grounding coil.

5.1. Power Model. Since the contact train transmission system includes multiple electric energy conversion processes, the equation for the comprehensive transmission efficiency $\eta$ of the contact traction system is

$$
\eta=\eta_{G} \cdot \eta_{M} \cdot \eta_{I} \cdot \eta_{C} \cdot \eta_{T}
$$

According to the measured data, the overall transmission efficiency of the contact traction system $\eta$ is generally 0.85 .

From this, the regenerative braking power of the train can be obtained as

$$
P_{z}=\frac{1000 C_{s} v_{s}}{3.6} \eta
$$

In addition, the traction power is

$$
P_{s}=\frac{1000 C_{s} v_{s}}{3.6 \eta} \text {. }
$$

5.2. Power Flow Control Method. The braking model works according to the given initial braking speed $v_{0}$ and the expected braking distance $s$. The calculated real-time speed $v_{s}$ is passed to the power model to obtain the reference power $P_{\text {ref. }}$ After comparing it with the measured power $P_{0}$, the error signal is transmitted to the PI. The control module generates an internally shifted phase angle $\varphi$ for adjusting the amount of transmitted power and realizes the amount of power adjustment by the PWM generator. Besides, the braking model compares the preset reference value of power phase angle $\theta_{P \text { ref }}$ with that of real-time power phase angle $\theta_{P}$ and transmits the error to PI controller to obtain the value of external phase angle $\gamma$, which is transmitted to PWM generator to realize the power direction adjustment. The control block diagram is shown in Figure 11. 
TABLE 2: Operating conditions of the ICPT system corresponding to the combined forces at each stage.

\begin{tabular}{lccc}
\hline & Unit force & ICPT system working condition & Time $(\mathrm{s})$ \\
\hline Stage 1 & $c=f_{q}-w_{i}-w_{r}-w_{s}-w_{0}$ & Forward transmission & $1 \sim 4$ \\
Stage 2 & $c=-w_{i}-w_{r}-w_{s}-w_{0}$ & Pause transmission & $0.5 \sim 1$ \\
Stage 3 & $c=-w_{i}-w_{r}-w_{s}-w_{0}-w_{z}$ & Reverse transmission & Uncertain \\
\hline
\end{tabular}

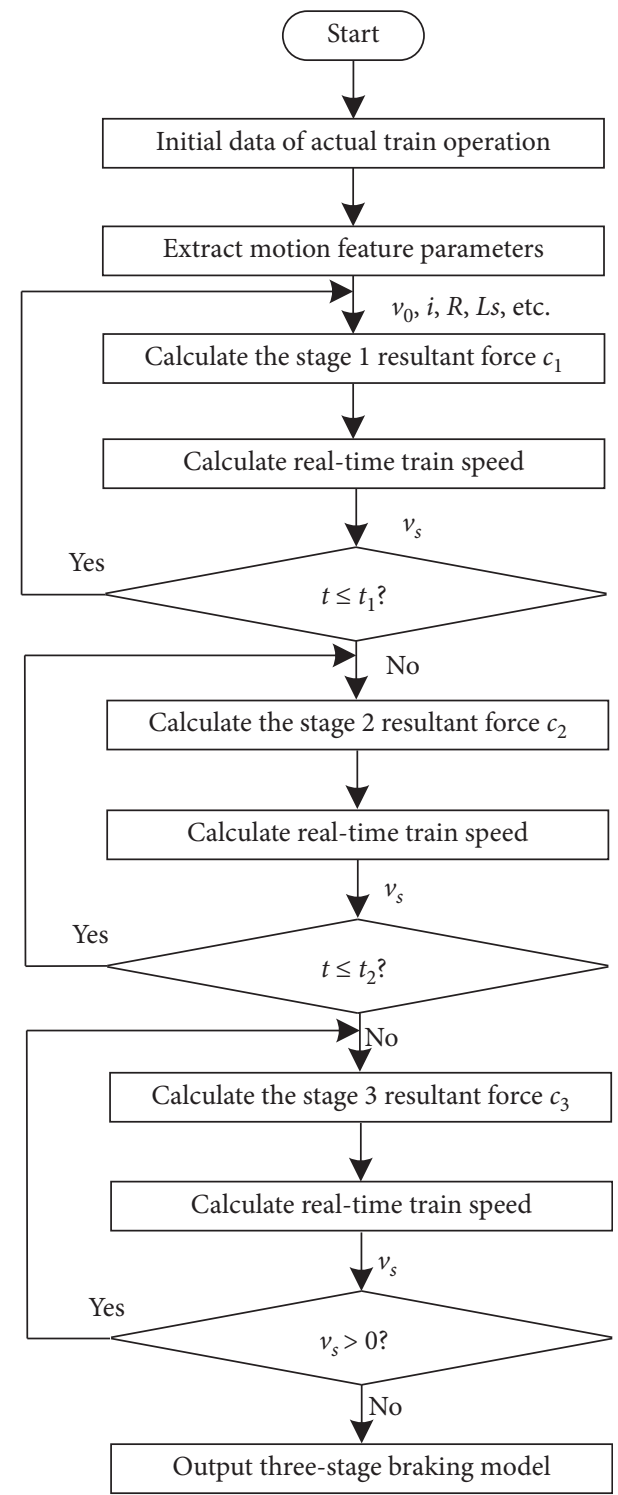

FIGURE 9: Flowchart of brake model construction.

It can be seen from the above that the internal phaseshift angles $\varphi_{1}$ and $\varphi_{2}$ of both sides determine the transmission power at the same time. The real-time reference power calculated according to the power model is compared with the measured power calculated from the measured voltage and current, and the error is transmitted to the PI control module to obtain the real-time internal shift phase angles $\varphi_{1}$ and $\varphi_{2}$. The phase-shift angle $\gamma$ is directly given by the braking model. The bilateral PWM generator can control the converter according to the phase-shift angle inside and out, so as to control the direction of power flow and the amount of power.
5.3. Coil Switching Control Method. The switching process of segmented coils can be divided into two parts: transient and steady state. Because the onboard coils of the highspeed rail are evenly distributed, they can be regarded as a whole, so the simplified switching process can be ignored. If the train coil is considered as a whole, the switching process of the ground coil can be analyzed based on the length of the train body and the braking distance. Therefore, this paper does not analyze the transient process, only the steady-state process.

Secondly, according to preliminary estimates, during the three-stage braking process of the high-speed rail pit stop, regenerative braking energy mainly exists in the third stage, and the braking distance in the third stage accounts for the highest proportion, about $70 \%$ of the entire braking process $80 \%$. At this time, the overall switching of the ground coil cannot guarantee the power requirements of the rail transit and the stability of the output voltage. Therefore, this paper uses the first two stages to switch the ground coil as a whole based on the preset braking distance, and the final stage divides the preset braking distance into four segments for control.

Table 3 lists the segment coil switch logic.

The schematic diagram of the ground coil switching at each stage is shown in Figure 12. This segmented switching coil method can ensure the voltage of the ground coil during the switching process on the premise of meeting the power requirements of rail transit, thereby improving the effectiveness.

The above analysis is based on the switching control method of the train-mounted and ground coils when the single-track single train brakes. However, in the actual operation of the station, there are still multiple trains entering and leaving the station simultaneously. Therefore, in order to improve the effectiveness of the preset switching control of the segmented coils and to meet the coordinated scheduling of regenerative braking energy between the medium-voltage DC bus and the energy storage device under multitrain operating conditions, further work has been done here. This paper analyzes the operating conditions of two trains with double tracks; with the purpose of collaborative regenerative energy scheduling and improving the feasibility of the preset control proposed, the preset switching control logic of multitrain segment coils is obtained.

In this section, the working conditions of $\mathrm{A}$ and $\mathrm{B}$ trains in and out of the station are divided into three scenes for analysis. The specific analysis results are shown in Table 4 .

In the valley filling charging scene, both trains are in regenerative braking conditions and the regenerative braking power is less than the set value of the trough transformer bottom charging power. The ground coils of the 


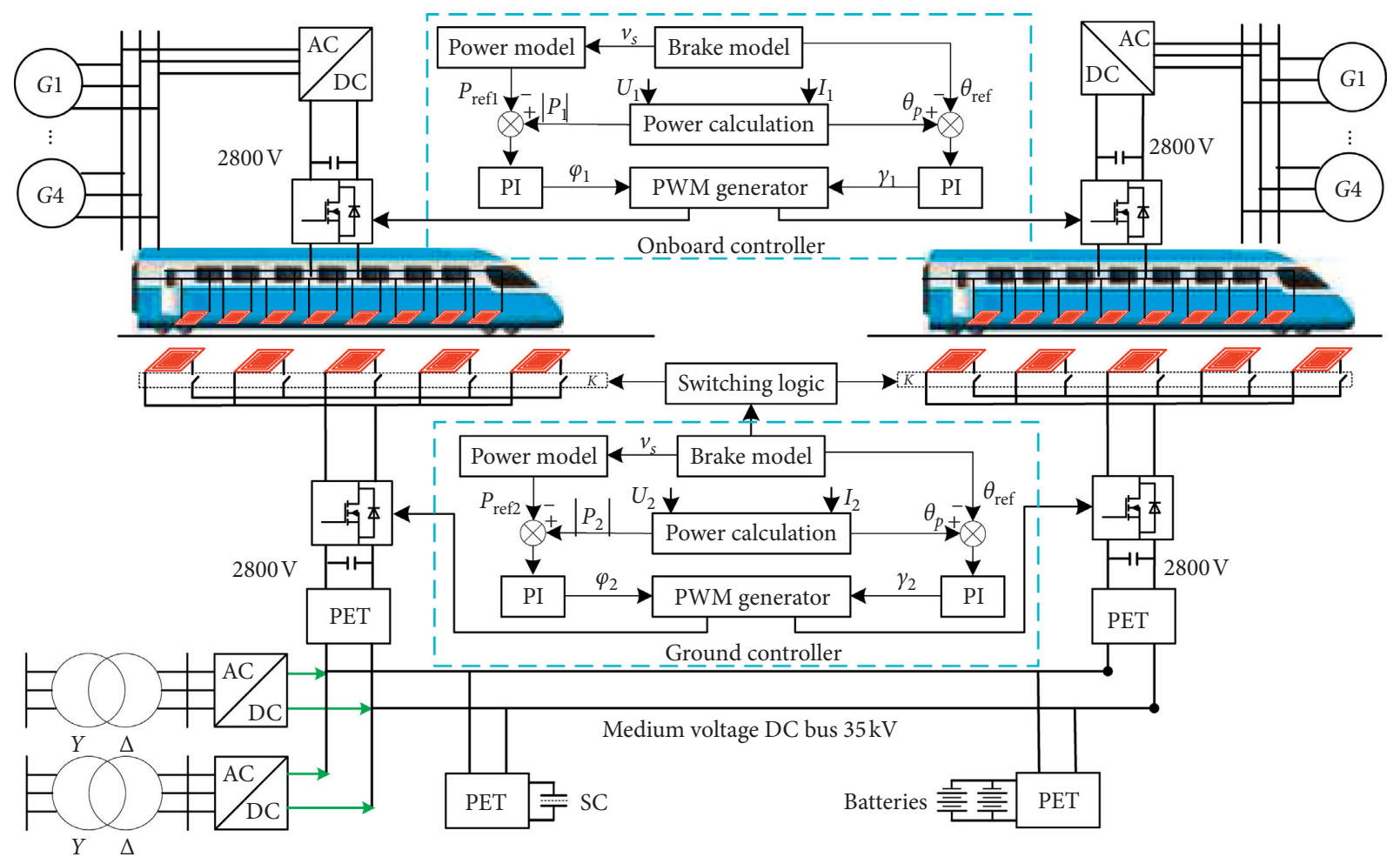

FIGURE 10: System overall control schematic diagram.

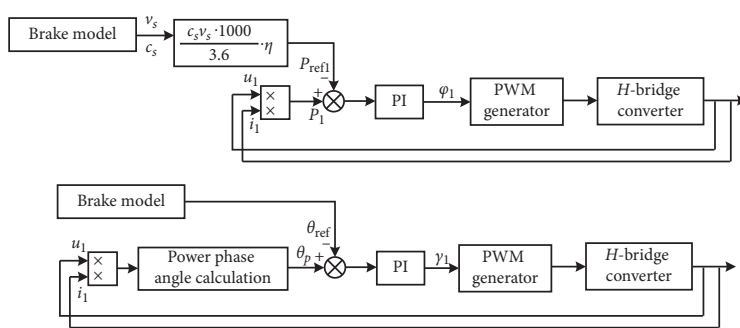

FIgURe 11: Power flow control block diagram.

A and B train's tracks are switched according to the preset switching control strategy of the coil proposed above. The DC bus and the energy storage device simultaneously recover the train regenerative braking energy.

In the peaking discharge scene, both trains are in regenerative braking conditions and the regenerative braking power is greater than the peak-shaving power setting value of the traction transformer. The ground coil of A's track is switched according to the proposed coil preset switching control strategy. The ground coil of B's track is closed. B enters the station by air braking or resistance braking. The DC bus is disconnected, and the energy storage device recovers the regenerative braking energy of the train until the capacity reaches the set value and charging stops.

In the power divert scene, $\mathrm{A}$ is in regenerative braking mode and B is in traction mode. The ground coil of A's track is switched according to the proposed coil preset switching control strategy. The energy storage device is suspended, the regenerative braking energy is fed back to the DC bus, and the regenerative braking power of $\mathrm{A}$ is diverted to $\mathrm{B}$ through the $\mathrm{DC}$ bus to fill the power required for starting.

\section{Simulation Results}

To verify the feasibility of the bidirectional ICPT system control method and the accuracy of the train braking model, as shown in Figures 13 and 14, a bidirectional ICPT system simulation model and a train braking simulation model were established in MATLAB/Simulink, respectively. See Table 5 for brake model simulation parameters.

For the coil design part, refer to the EMU parameters in Table 1. The train formation of CR400BF EMU is $4 \mathrm{M} 4 \mathrm{~T}$, each motor train is equipped with four electric motors with a rated power of $650 \mathrm{~kW}$, and the total installed power is $10.4 \mathrm{MW}$. Considering that the transmission power of the single-coil ICPT system is about $350 \mathrm{~kW}$ (when the rated working voltage is $2800 \mathrm{v}$ ), each motor train is equipped with 8 magnetic induction coupling coils, and every two coils are connected in parallel to supply power to a motor to ensure the entire train operation.

Therefore, this paper uses a $350 \mathrm{~kW}$ bidirectional ICPT system simulation prototype for verification. The system simulation parameters are shown in Table 6.

The simulation results are as follows.

Figure 15(a) is the train braking curve obtained by simulation according to the three preset times and initial braking speed in Table 5, and then the power curve shown in Figure 15(b) is obtained by simulation based on this. In the first stage, the train keeps traction, and the power decreases gradually with the increase of speed. In the second stage, the reference power of the train is 0 ; in the third stage, the train 
TABLE 3: Segmented coil switching logic.

The ground coil is turned on as a wh
The ground coil is turned off as a whe
$\begin{aligned} & \text { Stage } 1 \\ & \text { Stage } 2 \\ & \text { Stage } 3\end{aligned}$ The preset distance of stage 3 is divided into four small sections
on the distance

(a)

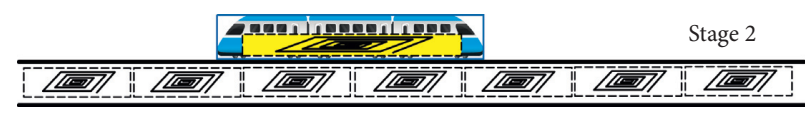

(b)

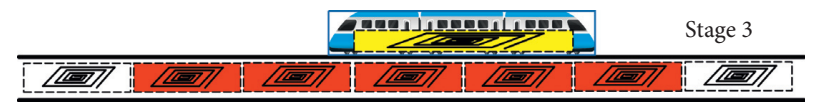

(c)

Figure 12: Ground coil switching diagram.

TABLE 4: The analysis of multitrain scenes.

\begin{tabular}{|c|c|c|c|c|}
\hline Type of scene & Trains status & Ground coil status & Bus side status & $\begin{array}{c}\text { Energy storage } \\
\text { device }\end{array}$ \\
\hline $\begin{array}{l}\text { Valley filling } \\
\text { charging }\end{array}$ & $\mathrm{A}$ and $\mathrm{B}$ are in regenerative braking & Both train tracks switch normally & $\begin{array}{l}\text { Energy } \\
\text { recovery }\end{array}$ & Charge \\
\hline $\begin{array}{l}\text { Peaking } \\
\text { discharge }\end{array}$ & $\mathrm{A}$ and $\mathrm{B}$ are in regenerative braking & $\begin{array}{c}\text { A track switches normally; B track } \\
\text { turns off the coil }\end{array}$ & Disconnect & Charge \\
\hline Power divert & $\begin{array}{c}\text { A is in regenerative braking and B is in traction } \\
\text { working condition }\end{array}$ & Both train tracks switch normally & Energy supply & Stop \\
\hline
\end{tabular}

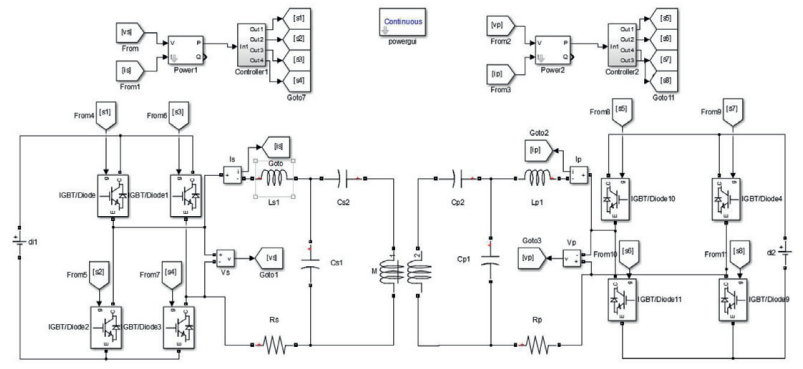

FIGURE 13: Simulation diagram of bidirectional ICPT system.

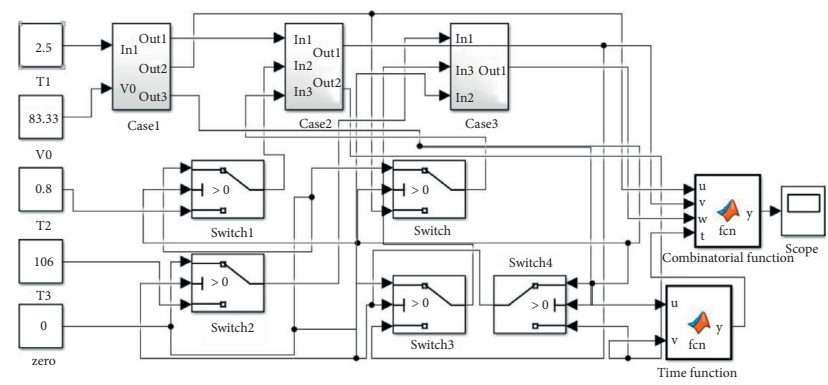

FIgURE 14: Simulation diagram of train brake model.

starts to brake, and the system power decreases with the decrease of the speed, which is consistent with the ICPT system working condition of each stage analyzed above, which proves the accuracy of the train braking model.
TABLE 5: Braking model simulation parameters.

\begin{tabular}{lc}
\hline Parameters & Value \\
\hline$v_{0} / \mathrm{m} / \mathrm{s}$ & 83.33 \\
$t_{n}\left(t_{1} / t_{2} /\right) / \mathrm{s}$ & $2.5 / 0.8 / 106$ \\
\hline
\end{tabular}

Figure 16 is a waveform diagram of the primary and secondary currents $i_{1}$ and $i_{2}$ and the primary and secondary voltages $u_{1}$ and $u_{2}$ when the ICPT system power is $350 \mathrm{~kW}$. It can be seen from the waveforms of $i_{1}$ and $i_{2}$ that the waveforms of $i_{1}$ and $i_{2}$ are both sine waves, indicating that the system is in resonance. When the system transmits the power in the forward direction, the primary current is larger than the secondary current, which is caused by system loss.

For the purpose of verifying the effectiveness of the control strategy proposed in this paper, a simulation process of switching the power transmission direction is added to the simulation system. It can be seen from Figure 17 that when the power transmission direction is switched at $0.01 \mathrm{~s}$, the voltage of the primary and secondary side changes little and is relatively stable. There are certain fluctuations in the primary and secondary side current, but the fluctuation time is very short $(<1 \mathrm{~ms})$, and the peak value of the fluctuation is about 1.05 times of the current when it is stable, which has little effect on the system. Figure 18 is the transmission power waveform diagram of the system after the system switches the power transmission direction at $0.0 .1 \mathrm{~s}$. It can be 
TABLE 6: Bidirectional ICPT system simulation parameters.

\begin{tabular}{lr}
\hline Parameters & Value \\
\hline$U_{1}(\mathrm{~V})$ & 2800 \\
$C_{p 1}(\mathrm{nF})$ & 146.5 \\
$C_{p 2}(\mathrm{nF})$ & 146.5 \\
$L_{p 1}(\mu \mathrm{H})$ & 48.4 \\
$L_{p 2}(\mu \mathrm{H})$ & 24.3 \\
$R_{p}(\Omega)$ & 1.5 \\
$M(\mu \mathrm{H})$ & 16 \\
$U_{2}(\mathrm{~V})$ & 2800 \\
$C_{s 1}(\mathrm{nF})$ & 146.5 \\
$C_{\mathrm{s} 2}(\mathrm{nF})$ & 146.5 \\
$L_{s 1}(\mu \mathrm{H})$ & 48.4 \\
$L_{s 2}(\mu \mathrm{H})$ & 24.3 \\
$R_{s}(\Omega)$ & 1.5 \\
$f(\mathrm{kHz})$ & 85 \\
\hline
\end{tabular}

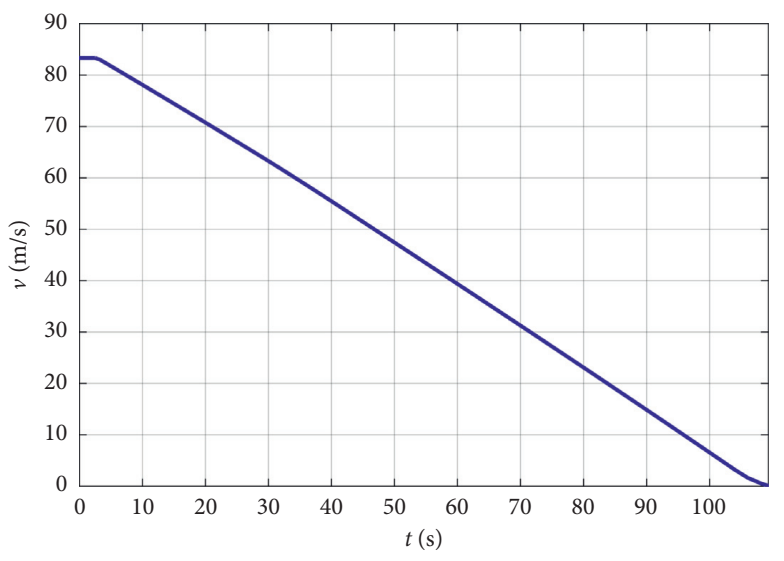

(a)

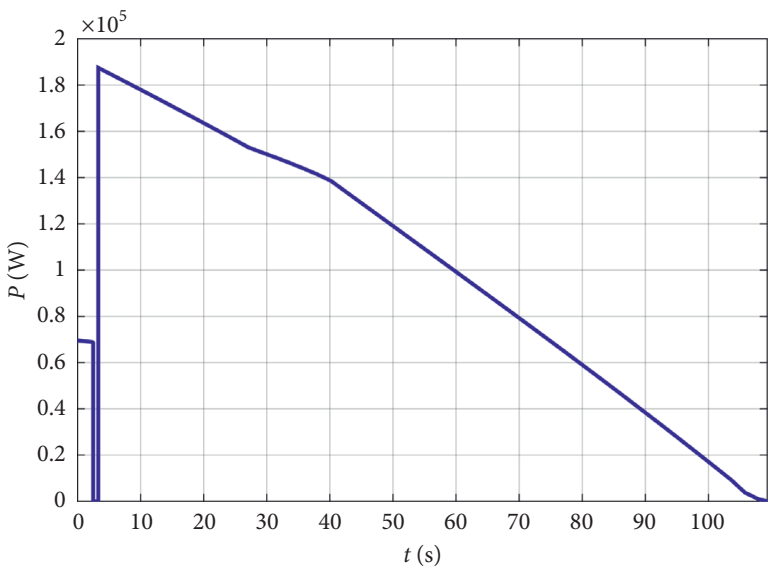

(b)

Figure 15: (a) Train brake curve. (b) System power curve.

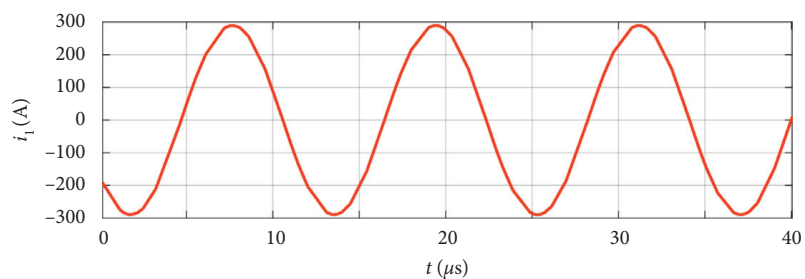

(a)

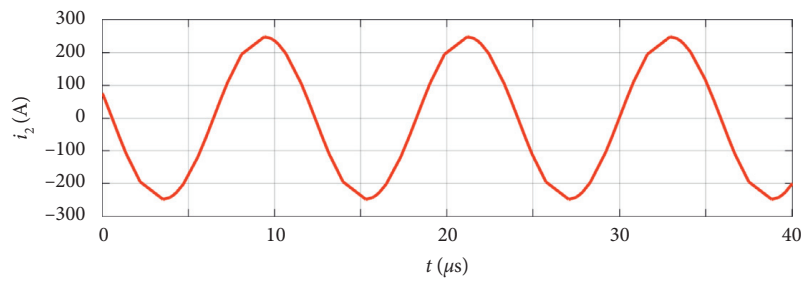

(c)

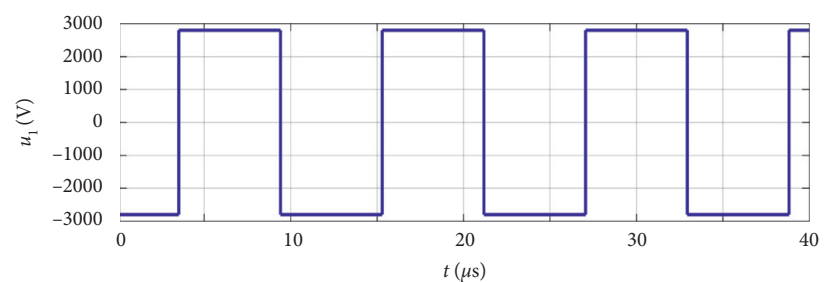

(b)

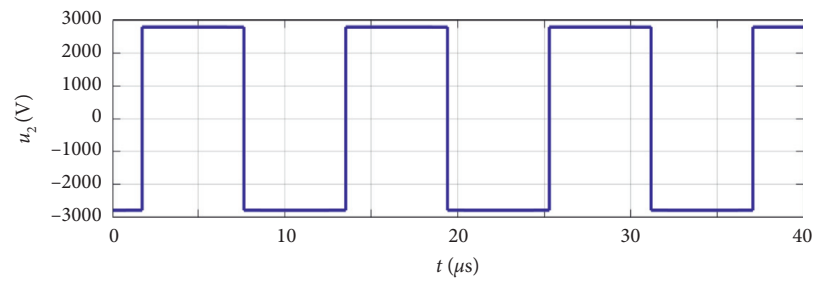

(d)

Figure 16: (a) Primary side current waveform at $350 \mathrm{~kW}$ power. (b) Primary side voltage waveform at $350 \mathrm{~kW}$ power. (c) Secondary side current waveform at $350 \mathrm{~kW}$ power. (d) Secondary side voltage waveform at $350 \mathrm{~kW}$. 


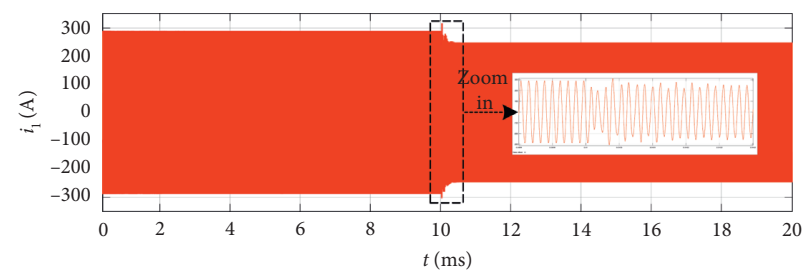

(a)

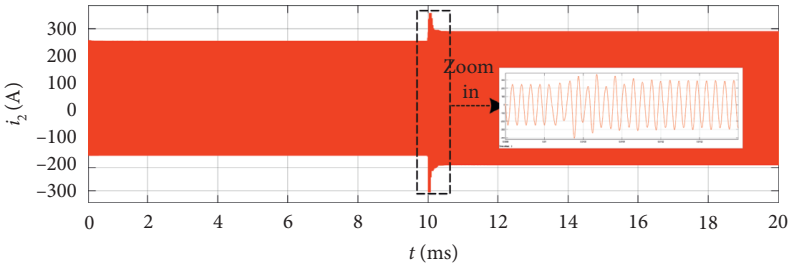

(c)

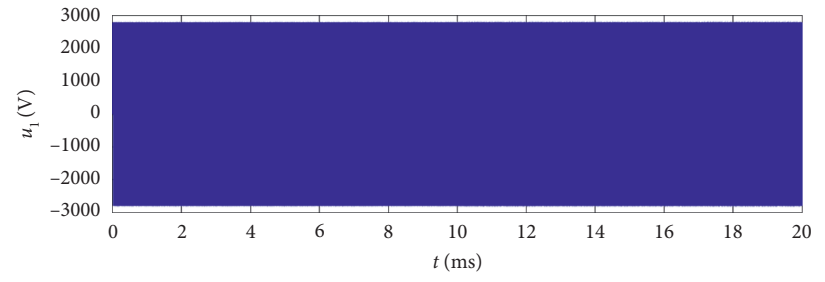

(b)

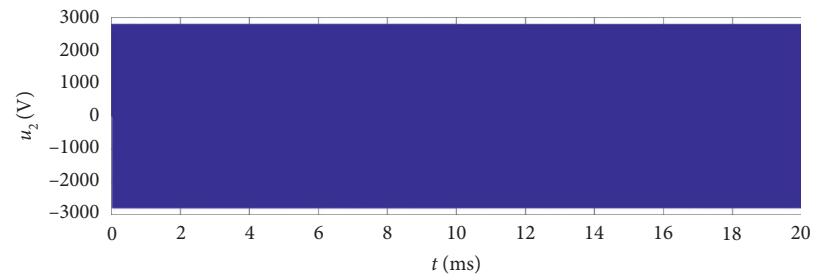

(d)

FIgURE 17: (a) Primary side current waveform when switching the power transmission direction at 0.01 s. (b) Primary side voltage waveform when switching the power supply direction at $0.01 \mathrm{~s}$. (c) Secondary side current waveform when switching the power transmission direction at $0.01 \mathrm{~s}$. (d) Secondary side voltage waveform when switching the power transmission direction at $0.01 \mathrm{~s}$.

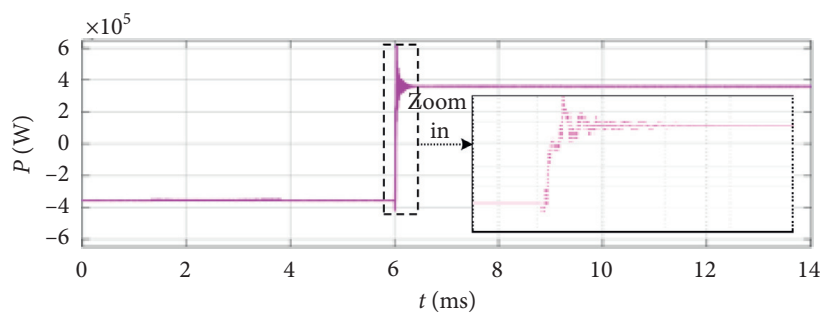

FIGURE 18: The waveform of system power when switching the power transmission direction at $0.01 \mathrm{~s}$.

seen from the figure that the power fluctuation time is also very short $(<1 \mathrm{~ms})$, and the peak power fluctuation is about $600 \mathrm{~kW}$. Figure 19 shows the simulation system transmission efficiency, which can reach about $89 \%$.

\section{Energy-Saving Estimate}

Taking common operating conditions as an example, $80 \%$ of the number of members is taken, and the per capita mass is $70 \mathrm{~kg}$. After calculation, the total mass of the train is $533.2 \mathrm{t}$.

Under the preset control strategy proposed in this paper, it can be seen through simulation that the simulation efficiency of the bidirectional ICPT system can reach $89 \%$. Based on the process of braking model calculation, combined with the operating efficiency of the ICPT system, it can be estimated that it can be recycled. The energy $Q$ is

$$
Q=\int_{t_{0}}^{t_{n}} P_{n} \eta \mathrm{d} t .
$$

In this section, energy-saving estimates are made when the initial braking speed of the train is $250 \mathrm{~km} / \mathrm{h}, 300 \mathrm{~km} / \mathrm{h}$, and $350 \mathrm{~km} / \mathrm{h}$. The regenerative braking energy that can be recovered during the entire braking process is shown in Table 7 .

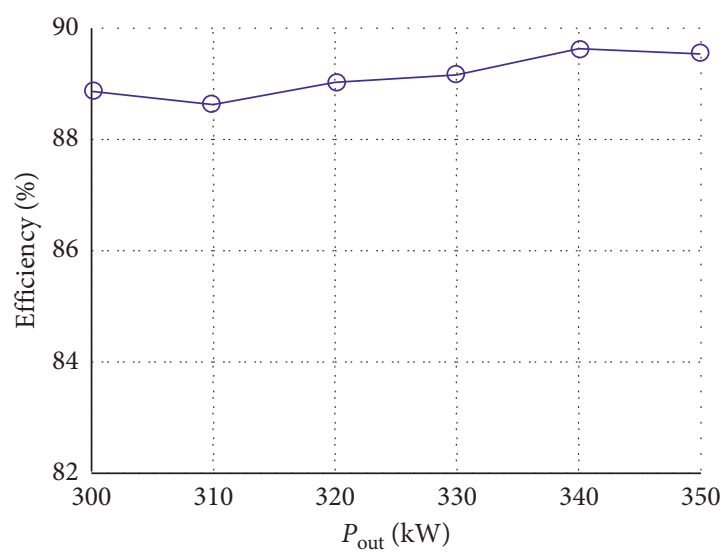

Figure 19: Simulation efficiency results for bidirectional ICPT system.

TABLE 7: Corresponding power recovery at the initial train speed.

\begin{tabular}{lcc}
\hline Initial velocity $(\mathrm{km} / \mathrm{h})$ & Total mass $(\mathrm{t})$ & Electric energy $(\mathrm{kW} \cdot \mathrm{h})$ \\
\hline 350 & 533.2 & 366.47 \\
300 & 533.2 & 269.8 \\
250 & 533.2 & 187.53
\end{tabular}


According to the measured data of regenerative braking energy in the actual operation of high-speed rail, literature 1 defines four types of typical processes based on two indicators: the duration of the regenerative braking process and the amplitude of the regenerative braking power [1]. In the process with the longest duration and the highest power, the braking lasted for $200 \mathrm{~s}$, and the total regenerative braking energy was $323.77 \mathrm{kWh}$. It can be seen from the above table that, based on the high-speed rail noncontact traction power supply system proposed in this paper, each single train lasts for about $110 \mathrm{~s}$ from braking to stopping, and the total regenerative braking energy is about $200-300 \mathrm{kWh}$. The measured data corresponds to this, which proves the modeling accuracy of this paper.

\section{Conclusion}

This paper proposes a preset bidirectional ICPT system segmented power supply preset control method that takes into account regenerative braking energy recovery. The steady-state model of the bidirectional ICPT system is analyzed, and the mathematical model of the train brake is established through the force analysis. The power preset control method and the segmented coil switching control method are proposed by using the above models. A $350 \mathrm{~kW}$ bidirectional ICPT system simulation prototype and a train braking simulation model were established in MATLAB/ Simulink. The results show that the ICPT system can operate stably when the power transmission direction is switched, and the system efficiency reaches $89 \%$, which verifies the feasibility of the proposed control method. In addition, the calculation results of the braking simulation model are consistent with the expected working conditions of each stage of the ICPT system, which proves the accuracy of the train braking model. Finally, an energy-saving estimate at multiple speed levels is carried out. The simulation results show that the estimated regenerative braking energy is consistent with the measured data, which proves the correctness of the braking model proposed in this paper.

\section{Data Availability}

The data used to support the findings of this study are available from the corresponding author upon request.

\section{Conflicts of Interest}

The authors declare that they have no conflicts of interest.

\section{Acknowledgments}

This work was supported by the National Natural Science Foundation of China (Project no. 51767015), the Gansu Provincial Natural Science Foundation of China (Gansu Provincial Science and Technology Plan, Project no. 18JR3RA117), and Lanzhou Jiaotong University-Tianjin University Joint Innovation Fund Project (Project no. 2019051).

\section{References}

[1] H. Hu and J. Chen, "Research on regenerative braking energy storage and utilization technology of high-speed railway," CSEE, vol. 40, pp. 246-256, 2020.

[2] M. Khodaparastan, A. A. Mohamed, and W. Brandauer, "Recuperation of regenerative braking energy in electric rail transit systems," IEEE Transactions on Intelligent Transportation Systems, vol. 20, no. 8, pp. 2831-2847, 2019.

[3] L. Shi, Z. Yin, L. Jiang, and Y. Li, "Advances in inductively coupled power transfer technology for rail transit," CES Transactions on Electrical Machines and Systems, vol. 1, no. 4, pp. 383-396, 2017.

[4] L. Pugi, A. Reatti, and F. Corti, "Application of wireless power transfer to railway parking functionality: preliminary design considerations with series-series and LCC topologies," Journal of Advanced Transportation, vol. 2018, p. 14, Article ID 8103140.

[5] J. H. Kim, B.-S. Lee, J.-H. Lee et al., "Development of 1-MW inductive power transfer system for a high-speed train," IEEE Transactions on Industrial Electronics, vol. 62, no. 10, pp. 6242-6250, 2015.

[6] S. B. Lee, S. Ahn, and I. G. Jang, "Simulation-Based feasibility study on the wireless charging railway system with a ferriteless primary module," IEEE Transactions on Vehicular Technology, vol. 66, no. 2, pp. 1004-1010, 2017.

[7] L. Pugi, F. Grasso, and G. Rossi, "Energy simulation of tramway systems, simplified and efficient models," 2018.

[8] R. Li, X. Zhao, J. Wang, and X. Li, "Research on energy distribution of regenerative braking in station for contactless traction power supply system based on bidirectional energy interaction ICPT system," IEEE Access, vol. 8, pp. 203930203944, 2020.

[9] S. Lin, D. Huang, and A. Wang, "Research on the regeneration braking energy feedback system of urban rail transit," IEEE Access, vol. 99, pp. 1-7, 2019.

[10] S. Wei, J. Wang, and H. Wang, "The braking mode simulation and analysis for high-speed railway," 2011.

[11] M. Khodaparastan, A. Mohamed, and W. Brandauer, "Recuperation of regenerative braking energy in electric rail transit systems," IEEE Access, vol. 1, pp. 1-17, 2019.

[12] Y. Lu, Y. Zhao, and X. Zhao, "Status analysis of regenerative braking energy utilization equipments in urban rail transit," 2017.

[13] S. Li, S. Wu, S. Xiang, Y. Zhang, J. M. Guerrero, and J. C. Vasquez, "Research on synchronverter-based regenerative braking energy feedback system of urban rail transit," Energies, vol. 13, no. 17, p. 4418, 2020.

[14] Y. Deng, Y. Li, and H. Chen, "Study on energy absorption scheme of rail transit," in Proceedings of the 2018 IEEE 3rd Advanced Information Technology, Electronic and Automation Control Conference, pp. 1430-1433, Chongqing, China, October 2018.

[15] W. Wei, H. Hu, K. Wang, and J. Chen, "Energy storage scheme and control strategies of high-speed railway based on railway power conditioner," Transactions on China Electrotechnical Society, vol. 34, pp. 1290-1299, 2019.

[16] Q. Ma, X. Guo, P. Luo, and Z. Zhang, "Coordinated control strategy design of new type railway power regulator based on super capacitor energy storage," Transactions on China Electrotechnical Society, vol. 34, pp. 765-776, 2019.

[17] K. Wang, X. Feng, J. Ren et al., "State of charge (SOC) estimation of lithium-ion battery based on adaptive square root 
unscented kalman filter," International Journal of Electrochemical Science, vol. 15, no. 9, pp. 9499-9516, 2020.

[18] K. Wang, W. Wang, L. Wang, and L. Li, "An improved soc control strategy for electric vehicle hybrid energy storage systems," Energies, vol. 13, no. 20, p. 5297, 2020.

[19] U. K. Madawala and D. J. Thrimawithana, "A bidirectional inductive power interface for electric vehicles in V2G systems," IEEE Transactions on Industrial Electronics, vol. 58, no. 10, pp. 4789-4796, 2011.

[20] Y. Tang, Y. Chen, U. K. Madawala, D. J. Thrimawithana, and H. Ma, "A new controller for bidirectional wireless power transfer systems," IEEE Transactions on Power Electronics, vol. 33, no. 10, pp. 9076-9087, 2018.

[21] F. Liu, K. Chen, Y. Jiang, and Z. Zhao, "Research on the overall efficiency optimization of the bidirectional wireless power transfer system," Transactions on China Electrotechnical Society, vol. 34, pp. 891-901, 2019.

[22] F. Liu, K. Chen, Y. Jiang, and Z. Zhao, "Phase synchronization of control signals based on perturbation and observation for bidirectional wireless power transfer system," 2018.

[23] T. Tan, K. Chen, Y. Jiang, L. Yuan, and Z. Zhao, "A bidirectional wireless power transfer system control strategy independent of real-time wireless communication," IEEE Transactions on Industry Applications, vol. 56, no. 2, pp. 1587-1598, 2020.

[24] L. Pugi, A. Reatti, and F. Corti, "Application of modal analysis methods to the design of wireless power transfer systems," Meccanica, vol. 54, pp. 321-331, 2019.

[25] M. Fan, L. Shi, Z. Yin, and L. Jiang, "Research on control strategy of segmented power supply for mobile inductive power transfer system," Transactions on China Electrotechnical Society, vol. 38, pp. 2112-2120+2226, 2018.

[26] H. Seung, K. Jae, and L. Jun, "Development of a $60 \mathrm{kHz}$, $180 \mathrm{~kW}$, over $85 \%$ efficiency inductive power transfer system for a tram," Energies, vol. 9, p. 1075, 2016.

[27] X. Zhang, J. Wang, Q. Yang, B. Wei, and S. Wang, "The power coupling mechanism and switching control for dynamic wireless power supply system of electric vehicle," Transactions on China Electrotechnical Society, vol. 34, pp. 3093-3101, 2019.

[28] X. Zhang, T. Cai, S. Duan et al., "A control strategy for efficiency optimization and wide ZVS operation range in bidirectional inductive power transfer system," IEEE Transactions on Industrial Electronics, vol. 66, no. 8, pp. 5958-5969, 2019.

[29] J.-Y. Lee, B.-M. Han, and M. Neath, "A bidirectional wireless power transfer EV charger using self-resonant PWM," IEEE Transactions on Power Electronics, vol. 30, no. 4, pp. 17841787, 2015.

[30] B. X. Nguyen, D. M. Vilathgamuwa, G. H. B. Foo et al., "An efficiency optimization scheme for bidirectional inductive power transfer systems," IEEE Transactions on Power Electronics, vol. 30, no. 11, pp. 6310-6319, 2015.

[31] C. Meng, Operation Diagram Based Traction Calculation for Multiple Trains, Beijing Jiaotong University, Beijing, China, 2019.

[32] Rail Transit Vehicle Interface Standards Committee of the IEEE Vehicular Technology Society, IEEE Guide for the Calculation of Braking Distances for Rail Transit Vehicles, The United States of America: the Institute of Electrical and Electronics Engineers, Inc., Beijing, China, 2009. 